Macroeconomic Evaluation of Labor Market Reform in Germany

Tom Krebs and Martin Scheffel 
IMF Working Paper

Research Department

\title{
Macroeconomic Evaluation of Labor Market Reform in Germany ${ }^{1}$ Prepared by Tom Krebs and Martin Scheffel
}

\author{
Authorized for distribution by Prakash Loungani
}

February 2013

\section{This Working Paper should not be reported as representing the views of the IMF. The views expressed in this Working Paper are those of the author(s) and do not necessarily represent those of the IMF or IMF policy. Working Papers describe research in progress by the author(s) and are published to elicit comments and to further debate.}

\begin{abstract}
In 2005 the German government implemented the so-called Hartz IV reform, which amounted to a complete overhaul of the German unemployment insurance system and resulted in a significant reduction in unemployment benefits for the long-term unemployed. In this paper, we use an incomplete-market model with search unemployment to evaluate the macro-economic and welfare effects of the Hartz IV reform. We calibrate the model economy to German data before the reform and then use the calibrated model economy to simulate the effects of Hartz IV. In our baseline calibration, we find that the reform has reduced the long-run (noncyclical) unemployment rate in Germany by 1.4 percentage points. We also find that the welfare of employed households increases, but the welfare of unemployed households decreases even with moderate degree of risk aversion.
\end{abstract}

JEL Classification Numbers:E21, E24, D52, J24

Keywords: Labor Market Reform, Unemployment, Welfare

Author's E-Mail Address: tkrebs@imf.org ; scheffel@mip.mtec.ethz.ch

\footnotetext{
${ }^{1}$ We thank our discussant, Romain Duval, seminar participants at various institutions and conferences, and the Office of the German Executive Director for useful comments. We also thank Sascha Zirra (Bundesagentur fuer Arbeit) for providing us with the data on job finding rates. We thank the Center for European Research (ZEW), Mannheim, for supporting our work on labor market reform. Tom Krebs also thanks the German National Science Foundation (DFG) for support under SFB884.
} 


\section{Introduction}

Over the period 1970-2005, unemployment rates in Germany had been steadily rising making the country a leading example of Eurosclerosis. In response to the dismal labor market performance, in 2003-2005 the German government implemented a number of wide-ranging labor market reforms, the so-called Hartz reforms. At the heart of the reform package was the Hartz IV law implemented in January 2005, which amounted to a complete overhaul of the German unemployment benefit system and resulted in a significant reduction in the level of unemployment benefits for the long-term unemployed. After a short spike mainly due to a change in measurement procedure, ${ }^{1}$ Germany's unemployment rate decreased from about 11 percent in 2005 to 7.5 percent in 2008 and barely moved during the Great Recession. The story about the "sick man of Europe" had turned into a story about the "German labor market miracle".

In this paper, we ask how much of the observed decline in the unemployment rate in the period 2005-2008 is a permanent reduction that can be attributed to the Hartz IV reform. Moreover, we analyze the consequences for economic growth taking into account the adjustment of physical capital and human capital. Finally, we investigate the welfare effects of Hartz IV. In particular, we ask how the expected life-time utility of different groups (employed, short-term unemployed, long-term unemployed) has been affected by the reform. To address these questions, we develop a macroeconomic model with heterogeneous households that emphasizes the trade-off between insurance and incentive, and use a calibrated version of the model economy to simulate the effects of the Hartz IV reform.

The model used in this paper combines the tractable incomplete-market model with hu-

\footnotetext{
${ }^{1}$ The Hartz IV reform entailed a significant change in the official measurement of unemployment, which added more than half a million workers to the pool of unemployed between January 2005 and March 2005 (see Bundesagentur fuer Arbeit, 2005) and resulted in a spike in the unemployment rate in 2005. More than 80 percent of these added unemployed workers lacked the equivalent of a high school degree.
} 
man capital developed in Krebs (2003) with a model of search unemployment along the lines of Ljungqvist and Sargent (1998). There is a large number of risk-averse, long-lived households who can invest in risk-free physical and risky human capital. Unemployed households decide on the intensity of job search and receive unemployment benefits that are not conditioned on (unobserved) search effort. We distinguish between short-term and long-term unemployment and assume that job search of the long-term unemployed is less effective than the job search of the short-term unemployed. We close the model assuming an aggregate production function with constant returns to scale that takes physical and human capital as input factors. ${ }^{2}$ Finally, the unemployment insurance system is financed with a linear tax on labor.

Our quantitative analysis shows that the Hartz IV reform has resulted in a substantial reduction in long-run (non-cyclical) unemployment. In our baseline calibration, the reform reduces the unemployment rate by 1.4 percentage points from a long-run value of 9 (the average for the period 2000-2004) to a new long-run value of 7.6 percent. As expected, the main force driving the reduction in unemployment is an increase in search effort that leads to higher job finding rates for both short-term and long-term unemployed, where the effect for the long-term unemployed is more pronounced. ${ }^{3}$ In short, the Hartz IV reform achieved its main goal, namely to reduce the non-cyclical unemployment by increasing the incentive to search for new jobs.

We also find that the reform leads to increase in long-run growth and an initial decline

\footnotetext{
${ }^{2}$ We use a closed-economy model with an aggregate resource constraint (market clearing) that determines wages and the interest rate endogenously. We think that it is desirable to include an analysis of possible real wage effects of the Hartz reform, something that would be missing if we had used a the standard small open economy framework. Clearly, the Germany's export sector is large (about half of GDP), and an extension of the current analysis that allows for current account effects of the Hartz reform is an important topic for future research.

${ }^{3}$ Data on the job finding rates for short-term and long-term unemployed before and after the reform support this prediction of the theory. See section 2 for more details.
} 
in real wages. Wages initially decrease because the reduction in unemployment benefits increases labor supply. ${ }^{4}$ There are two reasons why economic growth goes up. First, the increase in employment increases output. Second, the return to human capital investment increases, which induces more investment in human capital stimulating growth. Human capital returns go up because the labor tax can be reduced due to the reduction in unemployment, and this effect dominates the initial decline in pre-tax wages. In our baseline calibration, annual long-run growth increases by about 0.1 percent.

Our quantitative welfare analysis shows that the Hartz IV reform creates winners and losers since the gains and losses of the reform are very unevenly distributed across the population. In Germany, unemployment benefit payments are financed through contributions to the unemployment insurance system levied on labor income, and reductions in unemployment benefits and/or unemployment therefore lead to reductions in this labor tax. We find that employed households win because the gain from reduced labor tax outweighs the welfare loss due to the decrease in unemployment insurance. The resulting welfare gain for employed households is equivalent to an increase of around 0.4 percent of lifetime consumption. In contrast, the situation is reversed for the long-term unemployed, who experience a cut in their unemployment benefits that is quite large. In our baseline calibration, the welfare loss of the long-term unemployed is around one percent of lifetime consumption. Finally, the short-term unemployed also lose, but their welfare loss is significantly smaller than the welfare loss of the long-term unemployed. These welfare losses experienced by the unemployed could explain why the reform has encountered so much resistance in large parts of the German population.

Our paper is most closely related to the large macro literature on jobs search and unem-

\footnotetext{
${ }^{4}$ We use an endogenous growth model in which the labor market reform affects the long-run growth rate of the economy, including the long-run growth rate of real wages. The real wage decline we discuss here is a decline relative to the long-run trend. See figure 8 for details.
} 
ployment insurance, where the common theme is the trade-off between insurance and incentive (Hansen and Imrohoroglu, 1992, and Ljungqvist and Sargent, 1998). We contribute to this literature in two ways. First, we introduce a human capital channel and emphasize the important distinction between short-term and long-term unemployed workers. Second, we develop a tractable framework with risk-averse households who make a search and a saving decision, and apply the framework to one of the most significant reforms of the unemployment insurance system in recent history, the Hartz IV reform. We are aware of only two macro studies analyzing this reform using a structural approach. Krause and Uhlig (2011) find unemployment effects of Hartz IV that are larger than the ones reported here, whereas Launov and Waelde (2012) suggest that Hart IV had relatively small unemployment effects. ${ }^{5}$

Our results are in line with the large body of work empirical work on labor market institutions/policy and labor market outcome using cross country data, which usually find a significant and large effect of unemployment benefits on unemployment (Layard, Nickell, and Jackson, 2005). ${ }^{6}$ In a similar vein, empirical work that analyzes the interaction between labor market policies/institutions and macro-economic shocks finds that the unemployment benefit system plays an important role in shaping labor market outcomes (Blanchard and Wolfers, 2000). Of course, the current paper abstracts from macroeconomics shocks and can therefore not speak to this interaction. Extending the current analysis to incorporate aggregate shocks is an important topic for future research.

\footnotetext{
${ }^{5}$ Neither study reports the implied search elasticity of unemployed workers, which plays a key role in our calibration strategy. Launov and Waelde (2012) argue that Hartz IV had only small effects on net replacement rates for most unemployed workers, a statement that is at odds with most studies of the reform and the OECD data used in this paper.

${ }^{6}$ More recent work that uses country panel data (Bouis, Causa, Dennou, Duval, Zdziemicka, 2012) also finds large and significant effects of unemployment benefits.
} 


\section{Labor Market Developments in Germany}

In this section, we briefly review the German labor market experience since the 1970s and discuss the main elements of the labor market reforms implemented in 2003-2005, the socalled Hartz reforms. Although our review briefly touches upon all aspects of the Hartz reforms, the formal analysis conducted in the rest of the paper only deals with one part of the reform package, Hartz IV. A more detailed account of the Hartz reforms can be found in Jacobi and Kluve (2006).

\subsection{Macroeconomic Performance}

Figure 1 shows the unemployment rate in Germany in the period 1970-2011. The graph suggests that the unemployment rate has a strong cyclical component, but also a trend component that has been rising since the 1970s until the mid 2000s. For example, the average unemployment rate in the 1970s was below 4 percent, and this average had increased to almost 9 percent in the period 1995-2005. Clearly, in the period 1970-2005 Germany had experienced a substantial increase in the non-cyclical component of the unemployment rate. This trend was then reversed in the mid 2000s, and the unemployment rate fell from its peak of almost 11 percent in 2005 to 7.5 percent in 2008 and barely moved during the Great Recession.

Figure 1 suggests that the Hartz IV reform implemented in 2005 reduced the unemployment rate. However, the unemployment rate is highly cyclical, and GDP growth was $2.5 \%$ in 2006 and $3 \%$ in 2007, far above the average growth rate of 1.1\% in the period 1992-2011. Further, Hartz IV is only one component of an entire reform package, and it is not clear how to separate the effects of Hartz IV from Hartz I-III. Of course, the timing seems to suggests that Hartz IV was mainly responsible for any positive effect of the reform on employment

since Hartz I-III were implemented in 2003-2004. However, this conclusion is only correct if 
the labor market adjustment to reform is immediate, a hypothesis that is not confirmed by the current analysis. Figure 1 also cannot speak to the welfare consequences of labor market reform. For these reasons, in this paper we take a structural approach and use a calibrated model economy to simulate the unemployment and welfare effects of Hartz IV.

In this paper, we emphasize that Hartz IV reduced the unemployment rate because it increased search effort and therefore job finding rates. There is evidence supporting this idea. The job finding rates for both the short-term unemployed and long-term unemployed has been very stable before the Hartz IV reform and then began to increase steadily until the year 2007, at which stage they remained relatively stable at a significantly higher level (see figure 2 and Bundesagentur fuer Arbeit, 2011). ${ }^{7}$ For the long-term unemployed, the quarterly job finding rate increased from 6.3 percent at the beginning of 2004 to 9.3 percent at the beginning of 2006, and then stayed at this higher level for the subsequent years. Similarly, the job-finding rate for the short-term unemployed increased substantially, but most of the rise occured in the period 2006-2008. The quantitative results derived from the calibrated model economy are in line with these observations. However, the quantitative results reported in section 5 also suggest that the increase in the job finding rate due to Hartz IV is less that the increase observed in the data, in particular for the short-term unemployed. ${ }^{8}$ Thus, our results are consistent with the idea that Hartz III also contributed to the increase in job finding rates by improving matching efficiency (Fahr and Sunde, 2009).

\footnotetext{
${ }^{7}$ The fact that the German job finding rate has only a negligible cyclical component has also been documented in Jung and Kuhn (2011), a finding that stands in contrast to the findings for the US (Shimer, 2005).

${ }^{8}$ The OECD reports the fraction of long-term unemployed (the incidence of long-term unemployment). In accordance with the model prediction, in the data this variable decreased after the reform. However, the data on the incidence of long-term unemployed are not well suited to "test" the basic mechanism for two reasons. First, this variable is heavily influenced by movements into and out of the labor force, which can be very different for short-term and long-term unemployed workers. Second, the variable has a strong cyclical component.
} 
Figure 3 shows the evolution of per capita output and real wages in the post-unification period 1992-2011. We see that per capita output grew modestly at an average annual rate of 1 percent. In this period, Germany went through three recessions, 1993, 2003-2004, and 2008-2009, and had two periods of strong economic expansion, 2004-2007 and starting in 2010, and one prolonged period of weak but positive GDP growth in 1994-2001. Real wages stagnated between 1992 and 2003, and then fell about 4 percent in the period 2004-2009.

\subsection{Labor Market Reforms: Hartz I-IV}

The dismal labor market performance and a tightening of the social security budget convinced the German government that a drastic policy reversal had to take place. As a consequence, the German government implemented in 2003-2005 a number of labor market reforms, the so-called Hartz reforms named after the chairman of the commission that worked out the reform package. ${ }^{9}$ The far reaching reform package had three ambitious goals: i) improve the services of the employment agencies (increase the matching efficiency), ii) activate the unemployed (provide better incentives to search for jobs), and iii) foster new employment opportunities with low tax wedges and deregulate the labor market (increase labor demand). Overall, the Hartz reforms constitute one of the most radical labor market reforms implemented by an advanced country. ${ }^{10}$

Hartz I and Hartz II took effect in Jan 1st, 2003. Their main objective was to reduce labor costs through wage subsidies and to create new employment opportunities. For example, these laws eliminated the social security tax for jobs paying up to 400 Euro per month (Minijob) and reduced social security contributions for jobs paying up to 800 Euro per month (Midi-jobs) and for firms hiring older workers. They also deregulated the labor market. In

\footnotetext{
${ }^{9}$ To gather public support for the reforms, the government took advantage of a scandal involving the employment agency, which had mis-reported the success of job placement on a large scale.

${ }^{10}$ Of course, most European countries introduced some type of labor market reform in the last 20 years, but they were either much more limited in scope or the implementation was much more gradual.
} 
particular, restrictions on temporary work agencies and fixed-term contracts were weakened and dismissal regulations were simplified and additional exceptions were introduced.

In Jan 1st 2004, Hartz III was enacted with the goal to increase the efficiency of the job placement service for the unemployed. To this end, the public employment agency was re-structured and a heavy emphasis was placed on quality control. Moreover, the German government adopted a more market-based approach by allowing the public employment agency to outsource services to private firms and by offering unemployed workers the option to choose private employment agencies. Finally, Hartz III improved the process of matching particular measures of active labor market policy to the needs of unemployed individuals.

The best-known part of the reform package, Hartz IV, was implemented in Jan 1st, 2005. It constituted a radical overhaul of the German unemployment benefit system. Before the reform, the system was characterized by very long period of Unemployment Benefit entitlement and an essentially unlimited, means-tested Unemployment Assistance and/or Social Assistance after the eligibility for Unemployment Benefits had expired. The Hartz IV reform merged Unemployment Assistance and Social Assistance into Unemployment Benefit II and reduced the benefits payments for most households previously receiving Unemployment Assistance/Social Assistance (i.e. for most of the long-term unemployed). ${ }^{11}$

The Hartz IV reform reduced entitlement duration and benefit levels for most households, but the extent of the reduction varies substantially across household groups. One way to aggregate this heterogeneity is to follow the OECD and to report the median net replacement rate for short-term unemployed households, defined as unemployment less than one year, and long-term unemployed households, defined as unemployment more than one year. Figure 4 shows the average net replacement rate for single households based on the OECD data (see

\footnotetext{
${ }^{11}$ In addition, the eligibility period for short-term unemployment benefits (Unemployment Benefit I) was reduced in February 2006, but this change was not officially a part of the Hartz-laws and had only a small effect on the average net replacement rate (see figure 4).
} 
section 5 for details). Clearly, Hartz IV had almost no effect on the net replacement rate of the short-term unemployed, but a very large effect on the net replacement rate of the long-term unemployed.

\section{Model}

This section develops the model and defines our concept of equilibrium. The framework combines the incomplete-market model with human capital developed in Krebs (2003) with a search model along the lines of Ljungqvist and Sargent (1998).

\subsection{Households}

Time is discrete and open ended. There is a unit mass of infinitely-lived households. In each period $t$, an individual households receives an idiosyncratic shocks, $s_{t}$, which has two components $s_{t}=\left(s_{1 t}, s_{2 t}\right)$. The first component, $s_{1 t}$, denotes the current employment status, and households are either employed or unemployed, and the unemployed can be either good job seekers or bad job seekers. We identify the good job seekers with the short-term unemployed and the bad job seekers with the long-term unemployed. Thus, we have $s_{1 t} \in\{E, S U, L U\}$, where $E$ stands for employed, $S U$ for short-term unemployed (unemployed and good job seeker), and $L U$ for long-term unemployed (unemployed and bad job seeker). Unemployed households search for new jobs with search intensity (effort) $l$, and they find a new job in the subsequent period with probability $p_{s u, e}(l)$ if they are short-term unemployed and

$p_{l u, e}(l)$ if they are long-term unemployed. We assume $p_{s u, e}(l) \geq p_{l u, e}(l)$ for all effort levels $l$, that is, short-term unemployed have a higher re-employment probability than long-term unemployed. At the beginning of any unemployment spell, the household is short-term unemployed, and then becomes long-term unemployed with a constant probability $p_{s u, l u}$. Employed households become unemployed with constant (and exogenous) probability $p_{e u}$. The second component of the idiosyncratic shock, $s_{2 t}$, represents wage risk, which is mod- 
eled as i.i.d. shocks to the individual stock of human capital (see below). The idiosyncratic shock $s$ is observed by the government, but individual search effort, $l$, is unobservable (moral hazard). Note that our specification implies that the process $\left\{s_{t}\right\}$ is a Markov process with stationary transition probabilities $\pi\left(s_{t+1} \mid s_{t}, l_{t}\right)$.

Households are risk-averse and have identical preferences that allow for a time-additive expected utility representation. We also assume that utility is separable in consumption and search effort, and that the current utility is given by $u\left(c_{t}, l_{t}, s_{t}\right)=\ln c_{t}-v\left(l_{t}\right)+d\left(s_{1 t}\right)$, where $v$ is the dis-utility from search, a strictly increasing and strictly convex function, and $d$ is a function that describes constant utility difference between the three states employment, short-term unemployment, and long-term unemployment. Expected life-time utility associated with a consumption-effort plan, $\left\{c_{t}, l_{t} \mid s_{0}\right\}$, for a household with initial shock $s_{0}$ is given by

$$
U\left(\left\{c_{t}, l_{t} \mid s_{0}\right\}\right)=E\left[\sum_{t=0}^{\infty} \beta^{t}\left(\ln c_{t}-v\left(l_{t}\right)+d\left(s_{1 t}\right)\right) \mid s_{0}\right]
$$

where $\beta$ is the pure discount factor. Note that the expectations in (1) is taken with respect to joint distribution that depends through the transition probabilities $p_{s u, e}\left(l_{t}\right)$ and $p_{l u, e}\left(l_{t}\right)$ on the effort choice $\left\{l_{t}\right\}$. Thus, we should write $E_{\left\{l_{t}\right\}}[$.$] , but for notational ease we suppress$ the dependence of expectations on effort choice.

At time $t=0$, the initial state of an individual household is $\left(k_{0}, h_{0}, s_{0}\right)$, where $k_{0}$ denotes the initial stock of physical capital and $h_{0}$ the initial stock of human capital. Households can invest in physical capital (save) and human capital. Employed households receive capital and labor income, $r_{k t} k_{t}$ and $r_{h t} h_{t}$, where $r_{k t}$ and $r_{h t}$ denote the rental rate of physical and human capital, respectively. For an employed household, the risk-free return to physical capital investment is $r_{k t}-\delta_{k}$ and the risky return to human capital investment is $r_{h t}-$ $\delta_{h}+\eta\left(s_{3 t}\right)$. Here $\delta_{k}$ and $\delta_{h}$ denote the (average) depreciation rate of physical capital and human capital, respectively, and $\eta$ is a shock to individual human capital that represents 
wage risk. Unemployed households receive unemployment benefits that are proportional to their human capital, $B_{t}=b\left(s_{1 t}\right) h_{t}$, an assumption that keeps the model tractable. Note that unemployment benefits, $b$, depend on the type of the unemployed household (good or bad job seeker), but do not depend on unobserved search effort $l_{t}$. To rule out large portfolio shifts of the unemployed, we further assume that the unemployed earn a return on physical capital investment that equals the return to human capital investment, that is, income of an unemployed household is $b\left(s_{1 t}\right)\left(k_{t}+h_{t}\right)$.

Households' sequential budget constraint reads

$$
c_{t}+k_{t+1}+h_{t+1}= \begin{cases}\left(1+r_{k t}-\delta_{k}\right) k_{t}+\left(1+(1-\tau) r_{h t}-\delta_{h}+\eta\left(s_{2 t}\right)\right) h_{t} & \text { if } s_{1 t}=e \\ \left(1+b\left(s_{1 t}\right)\right)\left(k_{t}+h_{t}\right) & \text { if } s_{1 t}=s u, \text { lu }\end{cases}
$$

where $\tau$ is the tax rate on labor income. The tax revenues from the labor income tax are used to finance unemployment benefit payments (see below). For given government policy, $\left\{b_{t}, \tau_{c t}\right\}$, households choose a plan $\left\{c_{t}, l_{t}, k_{t}, h_{t}\right\}$ that maximizes (1) subject to the constraint $(2)$.

\subsection{Firms}

There is one all-purpose good that can be consumed or invested in physical capital or human capital. Production takes place under the aggregate production function $Y_{t}=F\left(K_{t}, H_{t}^{e}\right)$, where $Y_{t}$ is aggregate output in period $t, K_{t}$ the aggregate physical capital stock employed by firms, and $H_{t}^{e}$ the aggregate stock of human capital employed by firms. We assume that $F$ is a standard neoclassical production function. In particular, it exhibits constant returns to scale.

There is a large number of identical firms that have access to the production function (3) and hire physical capital and human capital (labor) in competitive markets at rental rates $r_{k}$ and $r_{h}$, respectively. In each period, firms hire physical capital and human capital so as 
to maximize profit

$$
F\left(K_{t}, H_{t}^{e}\right)-r_{k t} K_{t}-r_{h t} H_{t}^{e}
$$

\subsection{Government}

The government pays out unemployment benefits and finances the transfer payments with a linear tax on labor income. We assume that the government runs a balanced budget in every period so that the government budget constraint reads:

$$
\tau E\left[r_{h t} h_{t}\right]=E\left[b\left(s_{2 t}\right) h_{t}\right]-E\left[\left(r_{k t}-b\left(s_{2 t}\right)\right) k_{t}\right]
$$

\subsection{Equilibrium}

Introduce the following new household-level variables:

$$
\begin{aligned}
w_{t} & =k_{t}+h_{t} \\
\theta_{t} & =k_{t} / w_{t} \\
r\left(\theta_{t}, s_{t}\right) & = \begin{cases}\theta_{t}\left(1+r_{k t}-\delta_{k}\right)+\left(1-\theta_{t}\right)\left(1+(1-\tau) r_{h t}-\delta_{h}+\eta\left(s_{2 t}\right)\right) & \text { if } s_{1 t}=e \\
b\left(s_{1 t}\right) & \text { if } s_{1 t}=s u, l u\end{cases}
\end{aligned}
$$

Here $w$ is the value of total wealth, financial and human, $\theta$ the share of total wealth invested in physical capital, and $r$ is the total return on investment (in human and physical capital). Note that $w_{t}$ is total wealth before asset have paid off and depreciation has taken place and $(1+r) w$ is total wealth after asset payoff and depreciation has occurred. Note also that the relevant state variable for an individual household now becomes $\left(\theta_{t}, w_{t}, s_{t}\right)$.

Using the new definitions, the household budget constraint can be written as

$$
w_{t+1}=\left(1+r\left(\theta_{t}, s_{t}\right)\right) w_{t}-c_{t}
$$

The household problem is now to choose a plan $\left\{c_{t}, w_{t}, \theta_{t}, l_{t}\right\}$ that maximizes (1) subject to (6). The budget constraint (6) in conjunction with the assumption of homothetic preferences 
(log-utility) is the key to the tractability of the model: individual households solve a Mertontype consumption-saving and portfolio problem, where is our setting there is an added effort choice. The solution to this class of problems is quite simple (see proposition 1).

Denote the aggregate stock of physical capital owned by households as $E\left[k_{t}\right]=E\left[\theta_{t} w_{t}\right]$. Similarly, denote the aggregate stock of human capital of employed households as and $E\left[h_{t} \mid s_{1 t}=e\right]=E\left[\left(1-\theta_{t}\right) w_{t} \mid s_{1 t}=e\right]$. In equilibrium, choices of firms and households have to be consistent (equilibrium in capital and labor market):

$$
\begin{aligned}
K_{t} & =E\left[\theta_{t} w_{t}\right] \\
H_{t}^{e} & =E\left[\left(1-\theta_{t}\right) w_{t} \mid s_{1 t}=e\right]
\end{aligned}
$$

A (sequential) competitive equilibrium is defined in the standard manner:

Definition For given government policy $\left\{b_{t}, \tau_{c t}\right\}$, a competitive equilibrium is a sequence of rentals rates, $\left\{r_{k t}, r_{h t}\right\}$, a family of individual household plans, $\left\{c_{t}, w_{t}, \theta_{t}, l_{t}\right\}$, and a sequence of firm choices, $\left\{K_{t}, H_{t}^{e}\right\}$, so that

i) for given rental rates $\left(r_{k t}, r_{h t}\right)$ the production choice $\left(K_{t}, H_{t}^{e}\right)$ maximizes profit $(3)$ in each period $t$.

ii) for given sequence of rental rates $\left\{r_{k t}, r_{h t}\right\}$ the individual plan $\left\{c_{t}, w_{t}, \theta_{t}, l_{t}\right\}$ maximizes expected lifetime utility (1) subject to the budget constraint (8)

iii) market clearing condition (7) holds in each period $t$

iv) the government budget constraint (4) holds.

A stationary competitive equilibrium is a competitive equilibrium in which aggregate ratio variables, like the capital-to-labor ratio and the unemployment rate, are constant, but aggregate variables like output and capital grow at a constant rate. The property of 
unbounded growth is an implication of the constant-returns-to scale assumption and the further assumption that the two input factors, physical capital and human capital, can be accumulated without limits. See the discussion in Krebs (2003) for a more detailed discussion of the equilibrium behavior of this class of endogenous growth models with idiosyncratic risk.

Note that equilibrium unemployment rates for the short-term and long-term unemployed, which we denote by $U_{g}$ and $U_{b}$, are defined through initial values and the transition probabilities in the standard way. The law of motion for the two unemployment rates is given by (16) below.

Finally, note that the aggregate resource constraint reads

$$
C_{t}+K_{t+1}+H_{t+1}=\left(1-\delta_{k}\right) K_{t}+\left(1-\delta_{h}\right) H_{t}+F\left(K_{t}, H_{t}^{e}\right)
$$

A standard argument shows that the government budget constraint (4) in conjunction with the household budget constraint (2) imply the resource constraint (9) under the assumption of competitive rental markets and constant returns to scale in production.

\section{Equilibrium Characterization}

In this section, we present the main theoretical results. Proposition 1 shows that the household problem has a simple solution. Proposition 2 provides a convenient characterization of equilibria that is used in the quantitative section to compute equilibria. Proofs of the two propositions are relegated to the Appendix. To ease the exposition, we only discuss a stationary equilibrium, but we note that in this paper we also solve for the dynamic adjustment path towards the new long-run equilibrium after the reform. 


\subsection{Household Problem}

The recursive formulation of the household maximization problem reads

$$
\begin{gathered}
V(w, \theta, s)=\max _{c, \theta^{\prime}, w^{\prime}, l}\left\{\ln c-v(l)+d(s)+\beta \sum_{s^{\prime}} V\left(w, \theta^{\prime}, s^{\prime}\right) \pi\left(s^{\prime} \mid s, l\right)\right\} \\
\text { s.t. } \quad w^{\prime}=(1+r(\theta, s)) w-c
\end{gathered}
$$

where the effort choice, $l$, is only relevant if $s_{1}=u$. In the Appendix, we show that the Bellman equation (9) has a simple solution. More precisely, the optimal portfolio choice, $\theta$, is independent of wealth, $w$, and consumption and next-period wealth are linear functions of current wealth:

$$
\begin{aligned}
c & =(1-\beta)(1+r(\theta, s)) w \\
w^{\prime} & =\beta(1+r(\theta, s)) w
\end{aligned}
$$

Moreover, the value function has the functional form

$$
V(w, \theta, s)=\tilde{V}(s)+\frac{1}{1-\beta} \ln (1+r(\theta, s))
$$

and the optimal portfolio choice and optimal search effort are the solution to the intensiveform Bellman equation

$\tilde{V}(s)=\max _{\theta^{\prime}, l}\left\{B-v(l)+d(s)+\frac{\beta}{1-\beta} \sum_{s^{\prime}} \ln \left(1+r\left(\theta^{\prime}, s^{\prime}\right)\right) \pi\left(s^{\prime} \mid s, l\right)+\beta \sum_{s^{\prime}} \tilde{V}\left(s^{\prime}\right) \pi\left(s^{\prime} \mid s, l\right)\right\}$

where the constant $B$ is defined as $B=\ln (1-\beta)+\frac{\beta}{1-\beta} \ln \beta$.

Proposition 1. The solution to the household maximization problem is given by (10), (11), and (12).

Proposition 1 is useful for two reasons. First, it reduces the problem of solving the Bellman equation (9) to the much simpler problem of solving the intensive-form Bellman 
equation (12). Second, it states that consumption is linear in wealth and portfolio choice and effort choice are independent of wealth. This property allows us to solve for the general equilibrium without knowledge of the endogenous wealth distribution (proposition 2).

\subsection{Equilibrium}

Define the aggregate capital-to-labor ratio $\tilde{K}=\frac{K_{t}}{H_{t}^{e}}$ and the intensive-form production function $f(\tilde{K})=F(\tilde{K}, 1)$. Under constant-returns-to-scale and perfect competition, profit maximization of firms implies that the rental rates become a function of the aggregate capitalto-labor ratio:

$$
\begin{aligned}
& r_{k}=r_{k}(\tilde{K})=f^{\prime}(\tilde{K}) \\
& r_{h}=r_{h}(\tilde{K})=f(\tilde{K})-\tilde{K} f^{\prime}(\tilde{K})
\end{aligned}
$$

The solution the intensive-form Bellman equation (12) in conjunction with the pricing conditions (13) define optimal portfolio and effort functions $\theta^{\prime}=\theta^{\prime}\left(s, \tilde{K}^{\prime}\right)$ and $l=l\left(s, \tilde{K}^{\prime}\right)$. In the Appendix we show that the market clearing condition (7) is equivalent to the intensiveform market clearing condition

$$
\tilde{K}^{\prime}=\frac{\sum_{s} \theta^{\prime}\left(s, \tilde{K}^{\prime}\right) \Omega(s)}{\left(1-U^{\prime}\right) \sum_{s}\left(1-\theta^{\prime}\left(s, \tilde{K}^{\prime}\right)\right) \Omega(s)}
$$

where $\Omega(s)$ is the share of aggregate total wealth held by households of type $s, U^{\prime}=U_{s u}^{\prime}+U_{l u}^{\prime}$ is the unemployment rate, and a prime indicates a next-period variable. Further, in the Appendix we also show that the law of motion for $\Omega$ is

$$
\Omega^{\prime}\left(s^{\prime}\right)=\frac{\sum_{s}\left(1+r\left(\theta^{\prime}\left(s, \tilde{K}^{\prime}\right), s^{\prime}, \tilde{K}^{\prime}\right)\right) \Omega(s)}{\sum_{s, s^{\prime}}\left(1+r\left(\theta^{\prime}\left(s, \tilde{K}^{\prime}\right), s^{\prime}, \tilde{K}^{\prime}\right)\right) \Omega(s)},
$$

Finally, the unemployment rates for the short-term and long-term unemployed, $U_{s u}$ and $U_{l u}$, follow the law of motion

$$
\begin{aligned}
U_{s u}^{\prime} & =p_{e, s u}\left(1-U_{s u}-U_{l u}\right)+p_{l u, s u} U_{l u}+\left(1-p_{s u, e}\left(l\left(s u, \tilde{K}^{\prime}\right)\right)-p_{s u, l u}\right) U_{s u} \\
U_{l u}^{\prime} & =p_{s u, l u} U_{s u}+\left(1-p_{l u, s u}-p_{l u, e}\left(l\left(l u, \tilde{K}^{\prime}\right)\right)\right) U_{l u}
\end{aligned}
$$


In summary, we have the following result:

Proposition 2. Any solution to (12)-(16) with $\Omega^{\prime}=\Omega$ and $\left(U_{s u}^{\prime}, U_{l u}^{\prime}\right)=\left(U_{s u}, U_{l u}\right)$ is a stationary competitive equilibrium.

\section{Quantitative Evaluation of Hartz IV Reform}

As discussed in section 2, in the period 2003-2005 the German government implemented a number of wide-ranging labor market reforms, the so-called Hartz reforms. In particular, the last part of the reform package, Hartz IV, reduced the benefit payments for a large fraction of the long-term unemployed. In this section, we calibrate the model to match a number of facts of the German economy before the reform, and then use the calibrated model economy to simulate the long-run effect of Hartz IV on unemployment, output, wages, and welfare. To this end, we discuss in section 5.1 the functional form assumptions and the calibration. Section 5.2 then presents the long-run results and also discusses the transitional dynamics. Section 5.3 considers the robustness of our results by conducting a sensitivity analysis.

\subsection{Calibration}

The basic model period is one quarter. We calibrate the model economy so that its stationary equilibrium matches some of the basic features of the German economy in the period 20002004 (before the Hartz IV reform).

\subsubsection{Search}

We use the standard convention and define long-term unemployment as any unemployment spell that lasts longer than 12 months. Thus, we choose the probability of transiting from $S U$ to $L U, p_{s u, l u}$, equal to 0.25 .

For the job search technology, we follow Hopenhayn and Nicolini (1997), Lentz (2009), 
and Shimer and Werning (2008) and assume an exponential specification:

$$
\begin{aligned}
& p_{\text {su,e }}(l)=1-e^{-\lambda_{s u} l} \\
& p_{l u, e}(l)=1-e^{-\lambda_{l u} l}
\end{aligned}
$$

We choose the values of $\lambda_{s u}$ and $\lambda_{l u}$ so that the corresponding job finding probabilities match the observed average transition rates in the period 2000-2004 for the short-term unemployed and long-term unemployed, respectively. The values for the quarterly transition probabilities are $p_{\text {su,e }}=.06$ and $p_{l u, e}=.24$ according to the data provided by the German employment agency (Bundesagentur fuer Arbeit), which yields $\lambda_{s u}=0.724$ and $\lambda_{l u}=0.229$.

We assume that dis-utility of search is

$$
v(l)=-\bar{v} l^{\gamma}
$$

It is well-known that with specification (17) and (18), the parameters $\lambda_{s u}, \lambda_{l u}$ and $\bar{v}$ are not separately identified. We therefore choose a numerically convenient normalization of $\bar{v}=1$. We choose $\gamma$ in conjunction with the utility difference between employment and unemployment to match given values for the search elasticity of short-term unemployed and long-term unemployed. We do this as follows.

We assume a constant utility difference between employment and unemployment that is the same for short-term and long-term unemployed: $d(e)=0$ (normalization) and $d(s u)=$ $d(l u)=d$. We choose the preference parameter $d$ together with $\gamma$ to match the elasticity of the job finding rate with respect to benefits payments for both short-term unemployed and long-term unemployed. For the US, there are a number of empirical micro studies estimating this elasticity. The best known study is Meyer (1990) who estimates an elasticity of -0.9, which is also used by Landais, Michaillat, and Saez (2010) for calibration purpose. Subsequent work using US data has found similar results for some groups of workers and lower values for other group of workers (for example, Meyer and Mok, 2007). There is much 
less work on this issue for Germany, but Hunt (1995) finds estimates for Germany that are similar to the US results. Addison, Centeno and Portugal (2008) use a structural search model and the European Community Household Panel (ECHP) to estimate the elasticity for several European countries, and they find values ranging from -1.14 to -1.66 for Germany. In this paper, we follow Meyer (1990), Hunt (1995), and Landais, Michaillat, and Saez (2010) and choose as target value an average elasticity of -0.9 for the short-term and long-term unemployed.

We are not aware of any study that estimates this elasticity separately for the short-term and long-term unemployed. However, work by Chetty (2008) shows that the effect of unemployment benefits on unemployment duration is much stronger for low-wealth individuals, an effect he calls the liquidity effect based on the assumption that low-wealth individuals are liquidity constrained. In the data and in our model the long-term unemployed are the low-wealth individuals. Using the estimates reported in Chetty (2008) and identifying the long-term unemployed with the low wealth individuals, we conclude that the search elasticity of the long-term unemployed is at least twice as large as the search elasticity of the short-term unemployed. We therefore choose $\gamma$ and $d$ so that the implied elasticities for the short-term unemployed and the long-term unemployed match i) an average value of -0.9 and ii) a value for the long-term unemployed that is twice as large as for the short-term unemployed, that is, we choose -0.6 for the short-term unemployed and -1.2 for the longterm unemployed. The corresponding values for the utility parameters are $d=0.294$ and $\gamma=2.774$

We choose the job separation rate, $p_{e, s u}$, so that the implied unemployment rate is equal the average unemployment rate in the period 2000-2004, namely 9 percent. This yields a job separation rate of $p_{e, s u}=0.0148$, which is in line with Jung and Kuhn (2011). Finally, we choose $p_{l u, s u}$ to match a given fraction of long-term unemployed in the unemployment pool. 
According to the OECD statistics, the share of long-term unemployment was 50 percent for the period 2000-2004, a value we match if $p_{l u, s u}=0.190$.

\subsubsection{Wage Risk}

We assume that human capital shocks, and therefore wage risk, is normally distributed: $\eta \sim N\left(0, \sigma^{2}\right)$. One can show (Krebs 2003) that this assumption in conjunction with the i.i.d assumption implies that the log of labor income of individual households follows approximately a random walk with innovation term $\epsilon \sim N\left(0,(1-\theta)^{2} \sigma^{2}\right)$. For the US, the random walk component of individual labor income has been estimated by a number of empirical studies using data drawn from the PSID, and estimates of $(1-\theta) \sigma$ for the US are in the range of .15 for annual wage changes, which amounts to quarterly standard deviation of 0.15/2 + 0.075. For Germany, Krebs and Yao (2010) and Krueger and Fuchs-Schuendel (2009) find similar values, and we therefore choose the value of the parameter $\sigma$ to yield $(1-\theta) \sigma=.075$ in equilibrium.

\subsubsection{Production}

We follow Krebs (2003) and use quarterly depreciation rates of $\delta_{k}=\delta_{h}=0.015$. We assume

a Cobb-Douglas production function, $F\left(K, H^{e}\right)=A K^{\alpha}\left(H^{e}\right)^{1-\alpha}$, and set the capital share of output to $\alpha=0.36$. We choose the technology parameter $A$ and the discount factor so that the model matches the output growth rate and saving rate in Germany before the reform, namely one percent economic growth and a saving rate of 20 percent. This yields $A=0.0656$ and $\beta=0.9847$.

\subsubsection{Unemployment Benefits}

We choose the unemployment benefit parameters $b_{s u}$ and $b_{l u}$ to match the net replacement 
rate for the short-term and long-term unemployed before the reform (the period 2000-2004), ${ }^{12}$ and use OECD data on net replacement rates. The OECD reports the net replacement rate for short-term and long-term unemployed, where long-term unemployment is defined as unemployment duration longer than one year. The Hartz IV reform clearly had different effects on different sub-groups of the short-term and long-term unemployed. However, neither the model nor the OECD data are detailed enough to capture all aspects of this heterogeneity. We therefore focus on net replacement rates of single households who had earnings before the job loss equals average earnings. The OECD reports the net replacement rate for two subgroups of this group of households, namely single households without children and single households with two children. We calibrate the parameters $b_{s u}$ and $b_{l u}$ so that the model matches the weighted average net replacement rate for these two groups, where the weight for the first group is set equal to the population weight of all households without children and the weight of the second group is set equal to the population weight of all households with children. For the period 2000-2004, this yields a net replacement rate of 0.63 for the short-term unemployed and 0.57 for the long-term unemployed. ${ }^{13}$

\subsection{Effects of Hartz IV Reform}

We now analyze the effect of the Hartz IV reform. The Hartz IV reform had almost no impact on the net replacement rate of the short-term unemployed, regardless of household type. It is therefore not surprising that the average net replacement rate we construct is the same before and after the reform for the short-term unemployed. In contrast, the net

\footnotetext{
${ }^{12}$ In the model, the net replacement rate is not $b$, but $b /\left((1-\tau) r_{h}\right)$, and we choose $b$ so that the implied value of $b /\left((1-\tau) r_{h}\right)$ matches the corresponding net replacement rate.

${ }^{13}$ The results are similar, at least in terms of the effect of Hartz IV on net replacement rates, if we take couples instead of singles as long as we weigh the group without children and the group with two children the same way. The OECD does not report net replacement rates for households with one child. Hartz IV had a larger effect on the net replacement rate of households with one child than it had on the net replacement rate of households with two children, and our weighing scheme therefore understates the effect of Hartz IV on net replacement rates.
} 
replacement rate for the long-term unemployed dropped sharply after the reform for all households without children. For our average measure, we find that the Hartz IV reform reduced the net replacement rate from 0.57 in the period 2000-2004 to 0.46 after the reform in 2005 (see also figure 4). Based on this evidence, we simulate the effects of Hartz IV assuming that it reduced the net replacement rate for the long-term unemployed from 0.57 to 0.46 and that it left the net replacement rate for the short-term unemployed unchanged.

\subsubsection{Macroeconomic Effects}

Table 2 presents the long-run effects of the Hartz IV reform on some of the main macroeconomic variables, where the long-run effects are computed by comparing the values in the stationary equilibrium before the reform (first column) with the values in the stationary equilibrium after the reform (second column). The first row of table 2 shows that the reform leads to a substantial reduction in the unemployment rate - from 9 percent before the reform to 7.60 percent after the reform. Thus, our analysis suggests that a significant part of the decrease in the unemployment rate observed in the period 2005-2008 (see figure 1) can be attributed to the Hartz IV reform and amounts to a permanent reduction in the unemployment rate.

The second and third rows of table 2 show the long-run equilibrium values of the job finding rate for the short-term and the long-term unemployed before and after the reform. As expected, these job finding rates increase since household exert more search effort in response to the reduction in unemployment benefits. We also note that, in percentage terms, the increase in the job finding for the long-term unemployed exceeds the increase for the short-term unemployed, a result that seems intuitive given that the long-term unemployed are more directly affected by the reform than the short-term unemployed. The increase in job finding rates for short-term and long-term unemployed is the main force behind the decrease in the unemployment rate reported in the first row of table 1 . In short, the Hartz 
IV reform achieved its main goal, namely to reduce the structural unemployment rate by increasing the incentive of the unemployed to search for new jobs.

As we mentioned before, the data on job finding rates (figure 2) are in line with the model prediction. However, a comparison of figure 2 and table 2 also shows that Hartz IV by itself cannot explain the entire increase in job finding rates observed in the data, in particular for the short-term unemployed. In other words, our analysis suggests that Hartz IV had large positive effects on job finding rates, but Hartz IV cannot account for all of the observed increase in job finding rates. Clearly, , improvements in matching efficiency due to Hartz III are a natural candidate for explaining the non-negligible residual.

Figure 5 shows the transitional dynamics of the unemployment rate after the reform. We see that it takes about 8 quarters for the unemployment rate to get half way to the new stationary equilibrium value. This persistence is mainly generated by the fact that the the unemployment rate and the fraction of long-term unemployed are state variables, and both variables take time to adjust to the new long-run equilibrium. The share of longterm unemployment in unemployment decreases from a long-run value of 50 percent before the reform to a new long-run value of 48 percent after the reform. Figure 6 shows the dynamic evolution of the unemployment rates of the short-term unemployed and long-term unemployed separately. We see that the dynamic adjustment process is very similar for both variables.

We also find that the reform leads to an increase in long-run growth and an initial decline in real wages. Wages decrease initially because the reduction in unemployment benefits increases labor supply. There are two reasons why economic growth goes up. First, the increase in employment increases output. Second, the return to human capital investment increases, which induces more investment in human capital stimulating growth. Human capital returns go up because the labor tax can be reduced due to the reduction in unemployment, and this 
effect dominates the initial decline in pre-tax wages. Table 2 shows that the increase in the annual long-run growth rate of the economy is about 0.1 percent. Figures 7 and 8 show the time paths of output growth and real wage growth.

\subsubsection{Welfare Effects}

The Hartz IV reform has two opposing effects on welfare of individual households and social welfare. On the one hand, there is a negative effect since the reform reduces insurance against unemployment risk. The long-term unemployed are most directly affected by this reduction in benefits, but also the short-term unemployed and even the employed take into account that there is a chance that some time in the future they might become long-term unemployed. On the other hand, the reform increases employment and therefore production. In our analysis, all employed households benefit directly from this output effect through the reduction in the labor income tax after the reform.

We conduct the welfare analysis as follows. We compute welfare (expected lifetime utility) for each group of households (employed, short-term unemployed, long-term unemployed) in the stationary equilibrium before the reform. We also compute welfare for each group of households after the reform taking into account the adjustment path of the economy towards the new stationary equilibrium (transitional dynamics). We do the same for social welfare, which we define as the population-weighted average of the welfare of the three groups of households. Finally, we translate the computed welfare changes into equivalent consumption units by computing the corresponding change in certainty consumption that would make households indifferent between no-reform and reform (Lucas, 2003). More precisely, if we let $\left\{c_{t}, l_{t} \mid s_{0}\right\}$ stand for the consumption-effort plan of a household of type $s_{0}$ before the reform and $\left\{\hat{c}_{t}, \hat{l}_{t} \mid s_{0}\right\}$ stand for the consumption-effort plan after the reform, then the welfare gain of the reform for households of type $s_{0}$, denoted $\Delta\left(s_{0}\right)$, is defined as the solution to

$$
U\left(\left\{\left(1+\Delta\left(s_{0}\right)\right) c_{t}, l_{t} \mid s_{0}\right\}\right)=U\left(\left\{\hat{c}_{t}, \hat{l}_{t} \mid s_{0}\right\}\right)
$$


where the utility function over planed is defined in (1).

Table 3 reports the welfare results. The first row shows that employed households are the winners of the reform: their welfare increases by 0.44 percent of lifetime consumption. For the employed households, the gain from the tax reduction outweighs the welfare loss due to the reduction in unemployment insurance. At the opposite end are the long-term unemployed: their welfare decreases by 0.74 percent of lifetime consumption. For the longterm unemployed, the direct loss of unemployment benefits is much stronger than the gain from the reduction in consumption taxes. Finally, the short-term unemployed are somewhere in between, but they also lose.

To understand better the two effects on welfare, we also show in table 2 the welfare loss that is due to the insurance loss. More precisely, we compute the change in welfare for each group of households assuming that the mean consumption growth rate is unchanged.

Table 3 also shows that the reform increased social welfare. Put differently, if we distributed more of the output gains to the unemployed and less to the employed, then the reform would benefit all households. However, in reality the employed households receive the output gains through a reduction in their contributions to the unemployment insurance system. ${ }^{14}$

\subsection{Sensitivity Analysis}

We conducted an extensive sensitivity analysis by changing a number of calibration targets, always one at a time. We found that our main results are surprisingly robust to moderate changes in all parameter values. However, substantial changes in either the targeted share of long-term unemployed or the job finding elasticity have significant effects on our results.

\footnotetext{
${ }^{14}$ We also computed the benefits rate that maximizes social welfare and found that this rate is lower than the post-reform benefit rate, but the welfare gains of this further benefit reduction are very small.
} 
For example, if we decrease the share of long-term unemployed before the reform to 0.4 , then the Hartz IV reform reduces the unemployment rate by $1.25 \%$ and for a share of 0.3 the unemployment reduction is only $1.0 \%$. Similarly, if we assume that the average search elasticity with respect to unemployment benefits is -0.8 , then the unemployment reduction due to Hartz IV is $1.28 \%$, and for an average elasticity of -0.5 the unemployment effect is only $0.87 \%$. Clearly, a value of -0.5 for the average elasticity is a lower bound for German economy before the reform.

\section{Conclusion}

In this paper, we used an incomplete-market model with search unemployment to evaluate the macro-economic and welfare effects of the Hartz IV reform. We calibrated the model economy to German data before the reform and then used the calibrated model economy to simulate the effects of Hartz IV. In our baseline calibration, we found that the reform reduced the German long-run unemployment rate by 1.4 percentage points. We also found that the welfare of employed households increases, but the welfare of both short-term and long-term unemployed households decreases even with moderate risk aversion (log utility).

The model used in this paper abstracted from a number of important channels through which unemployment benefits may affect output, and incorporating these channels into the analysis is an important task for future research. For example, unemployment benefits adversely affect worker productivity and output if skills are lost during unemployment spells. On the other hand, unemployment benefits can increase productivity and output if they increase matching efficiency (Acemoglu and Shimer, 2000). Finally, the current analysis does not take into account aggregate demand channels, which is likely to be an important issue for understanding the dynamic adjustment of unemployment and output towards their long-run equilibrium values. 
This paper confined attention to one aspect of the entire reform package implemented in Germany in 2003-2005, namely the reduction in unemployment benefits. However, the Hartz reforms also increased matching efficiency, reduced tax wedges, and deregulated the German labor market. Incorporating these elements into the analysis is important for providing a comprehensive assessment of the labor market impact of the Hartz reforms.

The tractability of the framework makes it an ideal vehicle for the analysis of the interaction between labor market institutions/policies and macroeconomics shocks. The results of such an analysis could provide a structural interpretation of the findings in Blanchard and Wolfers (2000). Similarly, such an extension of the analysis could shed light on the empirical results that the short-run output-unemployment elasticity (Okun's law) varies across countries (Ball, Leigh, and Loungani, 2012). Further, it would allow for a formal assessment of the contribution of the Hartz reforms to the good performance of the German labor market during the Great Recession (Burda and Hundt, 2011).

Finally, in this paper we made the ad-hoc assumption that unemployment benefits are proportional to human capital (labor income) and therefore ruled out by assumption the use of more sophisticated (non-linear) policies. There is large literature on optimal unemployment insurance (Hopenhayn and Nicolini, 1997, and Shimer and Werning, 2008) that allows government policy to be a general function of observable variables. In this line of research, government policy is only constrained by the unobservability of search effort (moral hazard). The application of this approach to the current framework is an important topic for future research. 


\section{Appendix}

\section{A.1 Proof of Proposition 1.}

The household maximization problem with moral hazard has probabilities depending on choices, in contrast to the class of problem analyzed in Stokey and Lucas (1989). However, the standard argument for the principle of optimality still applies. Similarly, another standard argument shows that the Bellman equation (9) has a unique solution in an appropriately defined function space (contraction mapping theorem). Guess-and-verify then shows that (11) solves (9) with optimal policy function defined in (10).

There is a technical issue regarding the construction of the appropriate function space since the economic problem is naturally an unbounded problem. To deal with this issue, one can, for example, follow Streufert (1990) and consider the set of continuous functions $B_{W}$ that are bounded in the weighted sup-norm $\|V\| \doteq \sup _{x}|V(x)| / W(x)$, where $x=(w, \theta, s)$ and the weighting function $W$ is given by $W(x)=|L(x)|+|U(x)|$ with $U$ an upper bound and $L$ a lower bound, and endow this function space with the corresponding metric. ${ }^{15} \mathrm{~A}$ straightforward but tedious argument shows that confining attention to this function space is without loss of generality. More precisely, one can show that there exist functions $L$ and $H$ so that for all candidate solutions, $V$, we have $L(x) \leq V(x) \leq H(x)$ for all $x \in \mathbf{X}$. This completes the proof of proposition $1 .^{16}$

\section{A.2 Proof of Proposition 2}

From proposition 1 we know that individual households maximize utility subject to the budget constraint. Thus, it remains to be shown that the intensive-from market clearing

\footnotetext{
${ }^{15}$ Thus, $B_{W}$ is the set of all functions, $V$, with $L(x) \leq V(x) \leq U(x)$ for all $x \in \mathbf{X}$.

${ }^{16}$ Alvarez and Stokey (1998) provide a different, but related argument to prove the existence and uniqueness of a solution to the Bellman equation for a class of unbounded problems similar to the one considered here, though without moral hazard.
} 
condition (14) is equivalent to the market clearing conditions (7) and that (15) and (16) are the equilibrium law of motions for $\Omega$ and $U$.

First, note that the solution to the household problem (8) only depends on the first component $s_{1}$, but not on the i.i.d. component $s_{2}$. Let $\tilde{w}_{t}=\left(1+r_{t}\right) w_{t}$ be total wealth in period $t$ after production and depreciation has taken place. The aggregate stock of physical capital held by households in period $t+1$ is

$$
\begin{aligned}
E\left[k_{t}\right] & =E\left[\theta_{t+1} w_{t+1}\right] \\
& =\beta E\left[\theta_{t+1}\left(1+r_{t}\right) w_{t}\right] \\
& =\beta \sum_{s_{1 t}} E\left[\theta_{t+1} \tilde{w}_{t} \mid s_{1 t}\right] \pi\left(s_{1 t}\right) \\
& =\beta \sum_{s_{1 t}} \theta\left(s_{1 t}\right) E\left[\tilde{w}_{t} \mid s_{1 t}\right] \pi\left(s_{1 t}\right) \\
& =\beta E\left[\tilde{w}_{t}\right] \sum_{s_{1 t}} \theta\left(s_{1 t}\right) \Omega\left(s_{1 t}\right) .
\end{aligned}
$$

The second line in (A1) uses the equilibrium law of motion for the individual state variable $w$, the third line is simply the law of iterated expectations, the fourth line follows from the fact that the portfolio choices only depend on $s_{1}$, and the last line is a direct implication of the definition of $\Omega$. A similar expression holds for the aggregate stock of human capital held by all households, $E\left[h_{t}\right]=E\left[\left(1-\theta_{t}\right) w_{t}\right]$, and the aggregate stock of human capital held by employed households, $E\left[h_{t} \mid s_{1 t}=e\right]=E\left[\left(1-\theta_{t}\right) w_{t} \mid s_{1 t}=e\right]$. Dividing the expression for $E\left[k_{t}\right]$ by the expression for $E\left[\left(1-\theta_{t}\right) w_{t} \mid s_{1 t}=e\right]$ proves the equivalence between (7) and (14).

Define by $\bar{r}\left(s_{1 t}, s_{1, t+1}\right)$ the expected investment return conditional on $s_{1}$. The law of motion for $\Omega$ can be found as:

$$
\begin{aligned}
\Omega_{t+1}\left(s_{1, t+1}\right) & =\frac{E\left[\tilde{w}_{t+1} \mid s_{1, t+1}\right] \pi\left(s_{1, t+1}\right)}{E\left[\tilde{w}_{t+1}\right]} \\
& =\frac{E\left[\left(1+r_{t+1}\right) \tilde{w}_{t} \mid s_{1, t+1}\right] \pi\left(s_{1, t+1}\right)}{E\left[\left(1+r_{t+1}\right) \tilde{w}_{t}\right]} \\
& =\frac{\sum_{s_{1 t}} E\left[\left(1+r_{t+1}\right) \tilde{w}_{t} \mid s_{1 t}, s_{1, t+1}\right] \pi\left(s_{1 t} \mid s_{1, t+1}\right) \pi\left(s_{1, t+1}\right)}{\sum_{s_{1 t}, s_{1, t+1}} E\left[\left(1+r_{t+1}\right) \tilde{w}_{t} \mid s_{1 t}, s_{1, t+1}\right] \pi\left(s_{1 t}, s_{1, t+1}\right)}
\end{aligned}
$$




$$
\begin{aligned}
& =\frac{\sum_{s_{1}}\left(1+\bar{r}\left(s_{1 t}, s_{1, t+1}\right)\right) E\left[\tilde{w}_{t} \mid s_{1 t}\right] \pi\left(s_{1 t}\right)}{\sum_{s_{1 t}, s_{1, t+1}}\left(1+\bar{r}\left(s_{1 t}, s_{1, t+1}\right)\right) E\left[\tilde{w}_{t} \mid s_{1 t}\right] \pi\left(s_{1 t}\right)} \\
& =\frac{\sum_{s_{1 t}}\left(1+\bar{r}\left(s_{1 t}, s_{1, t+1}\right)\right) \Omega\left(s_{1 t}\right)}{\sum_{s_{1 t}, s_{1, t+1}}\left(1+\bar{r}\left(s_{1 t}, s_{1, t+1}\right)\right) \Omega\left(s_{1 t}\right)}
\end{aligned}
$$

where the second line uses the equilibrium law of motion for the individual state variable $x$, the third line is simply the law of iterated expectations, the fourth line follows from the fact that portfolio choices only depend on $s_{1}$ in conjunction with the definition of $\bar{r}$, and the last line is a direct implication of the definition of $\Omega$. This shows that the law of motion for $\Omega$ is (15). The law of motion (16) for $U$ is obvious. This completes the proof of proposition 2 .

\section{A.3 Computation}

To compute stationary equilibria, we use proposition 2 , that is, we solve the equations (12)-(16) with $\Omega^{\prime}=\Omega$ and $\left(U_{s u}^{\prime}, U_{l u}^{\prime}\right)=\left(U_{s u} U_{l u}\right)$. The max problem (12) is solved using the first-order conditions approach for portfolio choice and effort choice. Thus, we find a stationary equilibrium by solving a low-dimensional non-linear equation system.

For the computation of the transitional dynamics, we iterate over the sequence of aggregate wealth shares and unemployment rates, that is, over sequences of the relevant aggregate state variable $\left(\Omega_{e}, \Omega_{s u}, \Omega_{l u}, U_{s u}, U_{l u}\right)$. Specifically, if we denote the aggregate state by $X=\left(\Omega_{e}, \Omega_{s u}, \Omega_{l u}, U_{s u}, U_{l u}\right)$, then the solution algorithm proceeds as follows:

Step 1: Compute the pre-reform and post-reform stationary equilibrium allocation and the respective lifetime utilities.

Step 2: Set the number of periods $T$ the economy needs to converge to the new stationary equilibrium. Guess a sequence of aggregate states, $\left\{X_{t}\right\}_{t=0}^{T}$, where the initial aggregate state and the final aggregate state correspond to their pre- and post-reform equilibrium values, respectively. 
Step 3: Given the sequence of aggregate states and the households' life time utility function in intensive form, we start at period $T$ and solve backwards for a time series of individual households portfolio and effort choices, households' intensive form lifetime utility, the aggregate capital-to-labor ratio, and the consumption tax rate.

Step 4: Given the time series for households' portfolio choices and effort choices and aggregate capital-to-labor ratio, we use the recursive formula (15) and (16) for the aggregate state variable to solve forward for a sequence of aggregate state variables $\left\{X_{t}\right\}_{t=0}^{T}$.

Step 5: If $\max \left\|\left\{X_{t}^{B}\right\}_{t=0}^{T}-\left\{X_{t}^{F}\right\}_{t=0}^{T}\right\|<t o l$, the backward and forward solutions converged and we have solved for the transitional dynamics of the endogenous variables; otherwise, update the guess for the evolution of the aggregate state variable $\left\{X_{t}^{B}\right\}_{t=1}^{T-1}=\left\{X_{t}^{F}\right\}_{t=1}^{T-1}$ and go back to step 3 .

Solving for the transitional dynamics, we find that setting $T=100$ is sufficient and that the algorithm converges within 5 iterations to a tolerance level tol $=1 e-8$. 


\section{References}

Acemoglu, D., and R. Shimer (2000) "Productivity Gains from Unemployment Insurance," European Economic Review 44: 1145-1224.

Addison, J., Centeno, M., Portugal, P. (2008) "Unemployment Benefits and Reservation Wages: Key Elasticities from a Stripped-Down Job-Search Model," IZA Discussion Paper.

Alvarez, F., and N. Stokey (1998) "Dynamic Programming with Homogeneous Functions," Journal of Economic Theory 82: 167-189.

Ball, L., Leigh, D., and P. Loungani (2012) "Okun's Law: Fit at 50?" IMF Working Paper.

Blanchard, O., and J. Wolfers (2000) "The Role of Shocks and Institutions in the Rise of European Unemployment: The Aggregate Evidence," Economic Journal 100: 1-33.

Bois, R., Causa, O., Demmon, C., Duval, R., and A. Zdziemicka (2012) "The Short-term effects of Structural Reform: An Empirical Analysis," OECD Working Paper.

Bundesagentur fuer Arbeit (2005) "Der Uebergang von der Arbeitslosen- und Sozialhilfe zur Grundsicherung fr Arbeitssuchende," Sonderbericht.

Bundesagentur fuer Arbeit (2011) "Der Arbeitsmarkt in Deutschland: Sockel- und Langzeitarbeitslosigkeit," Arbeitsmarktberichterstattung.

Burda, M. and J. Hunt (2011) "What Explains the German Labor Market Miracle in the Great Recession?" NBER Working Paper.

Chetty, R. (2008) "Moral Hazard vs Liquidity and Optimal Unemployment Insurance," Journal of Political Economy 116: 173-234.

Fahr, R., and U. Sunde (2009) "Did the Hartz Reforms Speed Up the Matching Process? A Macro-Evaluation Using Empirical Matching Functions," German Economic Review 10, 284-316.

Hansen, G., and A. Imrohoroglu (1992) "The Role of Unemployment Insurance in an Economy with Liquidity Constraints and Moral Hazard," Journal of Political Economy 100: 118-142.

Hopenhayn, H., and J. Nicolini (1997) "Optimal Unemployment Insurance," Journal of Political Economy 105: 412-438.

Hunt, J. (1995) "The Effect of Unemployment Compensation on Unemployment Duration in Germany," Journal of Labor Economics 13: 88-120. 
Jacobi, L., and J. Kluve (2006) "Before and After the Hartz Reforms: The Performance of Active Labor Market Policy in Germany," IZA Discussion Paper.

Jung, P., and M. Kuhn (2011) "The Era of US-Europe Labor Market Divide: What Can We Learn?", Working Paper.

Krause, M., and H. Uhlig (2011) "Transitions in the German Labor Market: Structure and Crisis," Deutsche Bundesbank Working Paper.

Krebs, T. (2003) "Human Capital Risk and Economic Growth," The Quarterly Journal of Economics 118: 709-744.

Krebs, T., and Y. Yao (2010) "Labor Income Risk in Germany," Working Paper.

Krueger, D., and N. Fuchs-Schuendeln (2009) "Inequality Trends for Germany in the Last Two Decades: A Tale of Two Countries," Review of Economic Dynamics 13: 103-132.

Landais, C., Michaillat, P., and E. Saez (2010) "Optimal Unemployment Insurance over the Business Cycle," NBER Working Paper

Launov, A., and K. Waelde (2012) "Estimating Incentive and Welfare Effects of NonStationary Unemployment Benefits," Working Paper.

Layard, R., Nickell, S., and R. Jackman (2005) Unemployment: Macroeconomic Performance and the Labour Market 2nd. edition, Oxford University Press, 2005.

Lentz, R. (2009) "Optimal Unemployment Insurance in an Estimated Job-Search Model with Savings," Review of Economic Dynamics 12: 37-57.

Lucas, R. (2003) "Macroeconomic Priorities," American Economic Review 93: 1-14.

Ljungqvist, L., and T. Sargent (1998) "The European Unemployment Dilemma," Journal of Political Economy 514-550.

Meyer, B. (1990) "Unemployment Insurance and Unemployment Spells," Econometrica 58: $757-782$.

Meyer, B., and W. Mok (2007) "Quasi-Experimental Evidence on the Effects of Unemployment Insurance from New York State," NBER Working Paper.

Shimer, R., and I. Werning (2008) "Liquidity and Insurance for Unemployed Workers," American Economic Review 98: 1922-1942.

Shimer, R. (2005) "The Cyclical Behavior of Equilibrium Unemployment, Vacancies, and Wages: Evidence and Theory," American Economic Review 95: 25-49. 
Streufert, P. (1990) "Stationary Recursive Utility and Dynamic Programming under the Assumption of Biconvergence," Review of Economic Studies 57: 79-97.

Stokey, N., and R. Lucas (1989) Recursive Methods in Economic Dynamics Harvard University Press, 1989. 
Table 1. Calibration

\begin{tabular}{|c|c|c|}
\hline Parameter & Meaning & Value \\
\hline$p_{e, s u}$ & transition probability $\mathrm{E} \rightarrow \mathrm{SU}$ & 0.0148 \\
\hline$p_{s u, l u}$ & transition probability $\mathrm{SU} \rightarrow \mathrm{LU}$ & 0.25 \\
\hline$p_{l u, s u}$ & transition probability LU $\rightarrow \mathrm{SU}$ & 0.19 \\
\hline$\lambda_{s u}$ & search efficiency of short-term unemployed & 0.724 \\
\hline$\lambda_{l u}$ & search efficiency of long-term unemployed & 0.229 \\
\hline $\bar{v}$ & utility parameter (normalization constant) & 1 \\
\hline$d$ & disutility of work & 0.293 \\
\hline$\gamma$ & curvature of disutility function & 2.774 \\
\hline$\beta$ & discount factor & 0.985 \\
\hline$\sigma$ & standard deviation of wage shocks & 0.075 \\
\hline$\delta_{k}$ & depreciation rate of physical capital & .015 \\
\hline$\delta_{h}$ & depreciation rate of human capital & .015 \\
\hline$\alpha$ & capital's share in output & .36 \\
\hline$A$ & total factor productivity & 0.0656 \\
\hline$b_{s u}$ & net replacement rate for short-term unemployed & 0.628 \\
\hline$b_{l u}$ & net replacement rate for long-term unemployed & 0.572 \\
\hline
\end{tabular}


Table 2. Macroeconomic Effects

\begin{tabular}{lcc}
\hline \hline & Pre-Reform & Post-Reform \\
\hline \hline & $9 \%$ & $7.760 \%$ \\
unemployment rate & $4.5 \%$ & $3.92 \%$ \\
unemployment rate (short-term unemployed) & $9 \%$ & $3.67 \%$ \\
unemployment rate (long-term unemployed) & 0.24 & 0.277 \\
job finding rate (short-term unemployed) & 0.06 & 0.077 \\
job finding rate (long-term) & $1 \%$ & $1.07 \%$ \\
growth & & \\
\hline \hline
\end{tabular}

Table 3. Welfare Effects in Percent of Lifetime Consumption

\begin{tabular}{lcc}
\hline \hline & Net Effect & Insurance Effect \\
\hline \hline Employed & $+0.439 \%$ & $-1.795 \%$ \\
Short-term Unemployed & $-0.132 \%$ & $-2.354 \%$ \\
Long-term Unemployed & $-.739 \%$ & $-2.948 \%$ \\
Social Welfare & $+0.361 \%$ & $-1.873 \%$ \\
\hline \hline
\end{tabular}


Figure 1: Unemployment Rate, Germany 1970 - 2011

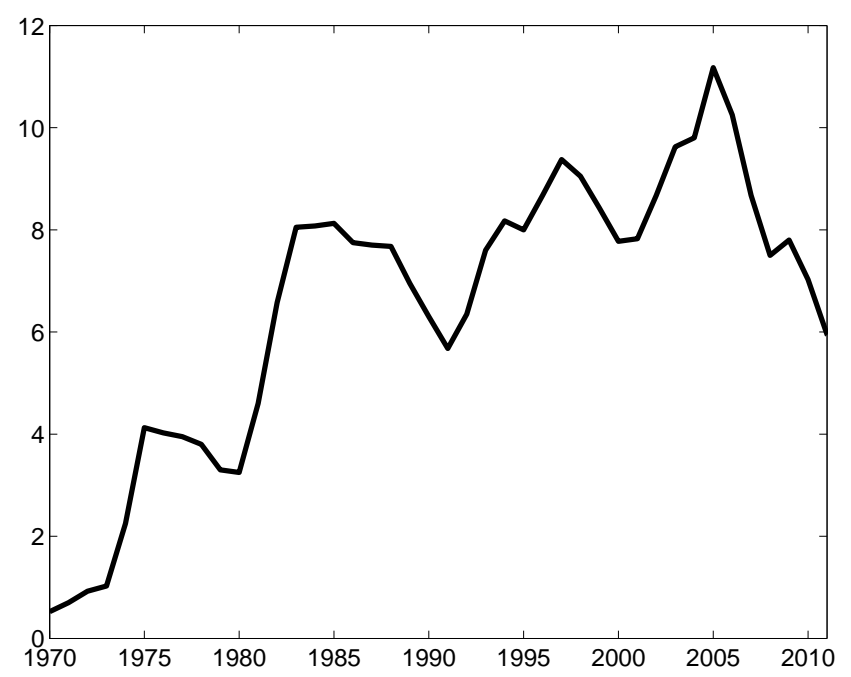

Source: OECD: 1970 - 1990, annual unemployment rate for West Germany; 1991 - 2011, annual harmonized unemployment rate for Germany.

Figure 2: Quarterly Job Finding Rates by Duration of Unemployment Spell, Germany 2000 - 2011

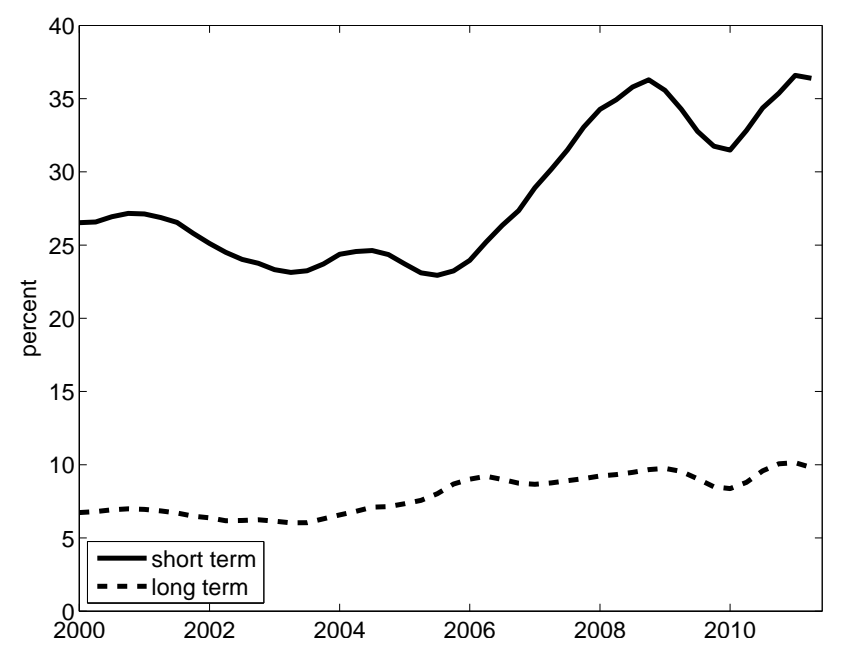

Source: Bundesagentur für Arbeit (2011). 
Figure 3: Real Wage and Real GDP per Capita $(1992=100)$, Germany 1992 - 2011

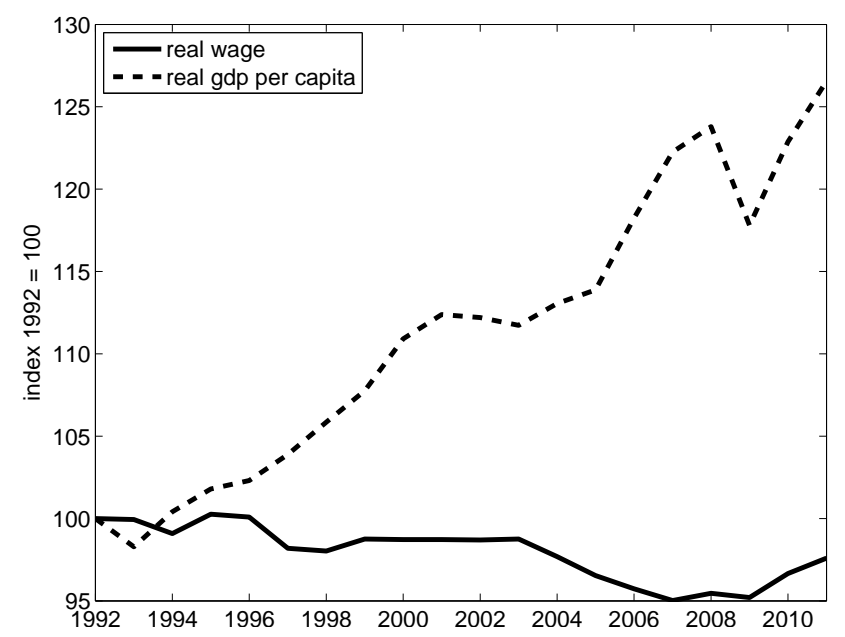

Sources: Statistisches Bundesamt: annual real wage index (series: Reallohnindex) and annual real GDP per capita (series: Bruttoinlandsprodukt) normalized to 1992.

Figure 4: Average Net Replacement Rate, Germany 2001 - 2010

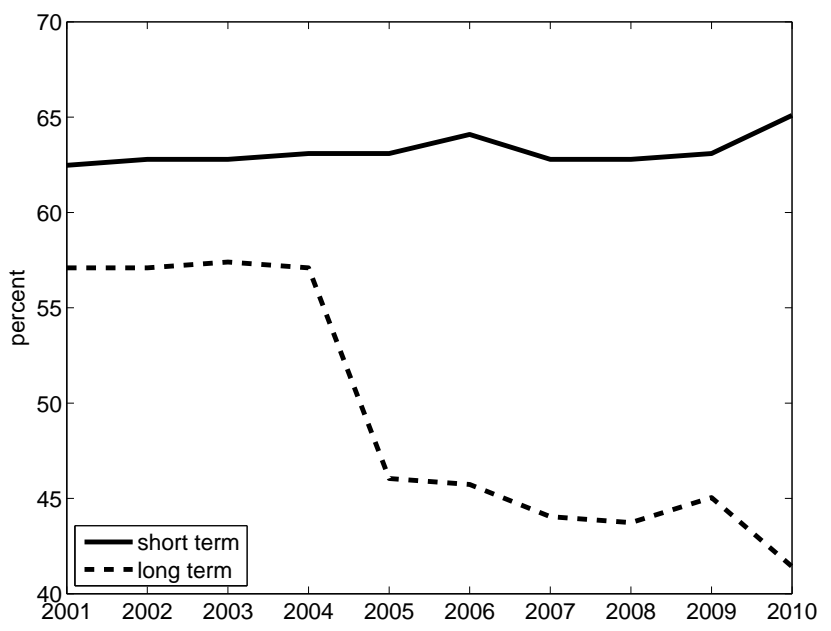

Sources: OECD. (1) net replacement rates: OECD Tax-Benefit Models, (2) population weights: OECD Family Database. 
Figure 5: Unemployment Rate

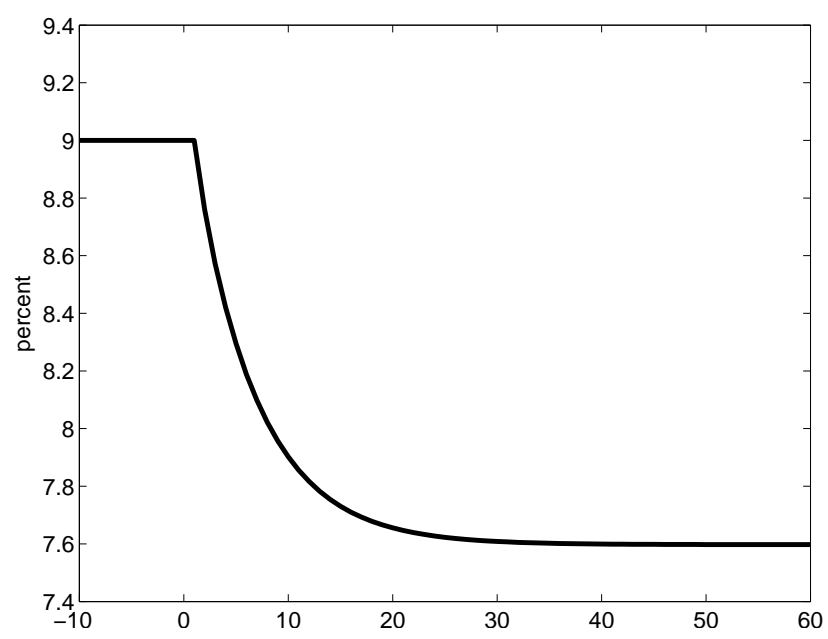

Figure 6: Unemployment Rate by Duration of Unemployment Spell

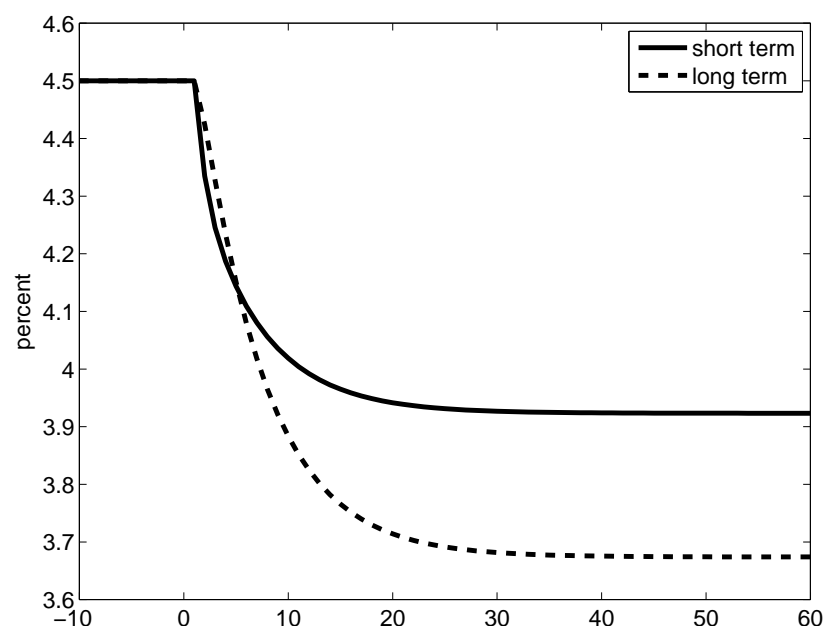


Figure 7: Annualized Growth Rate of Aggregate Output

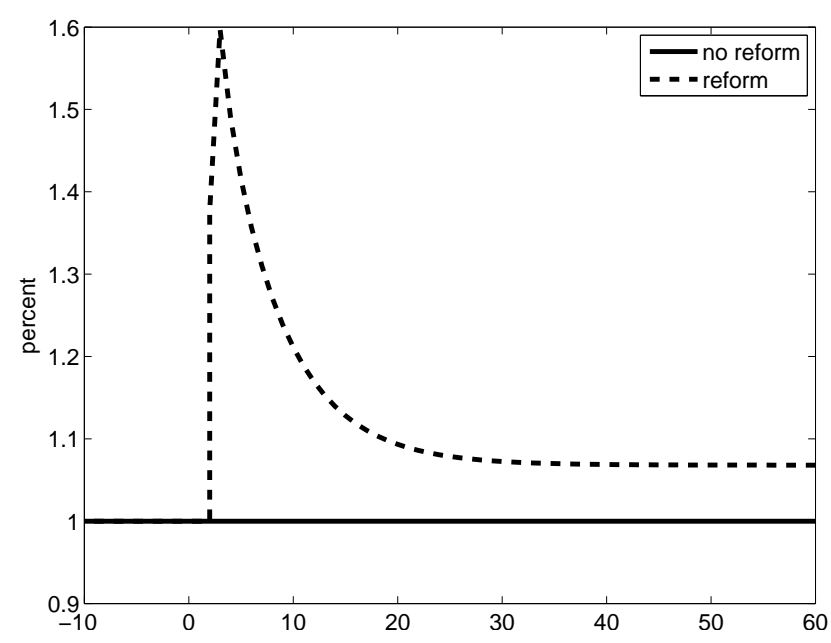

Figure 8: Annualized Growth Rate of Average Wage

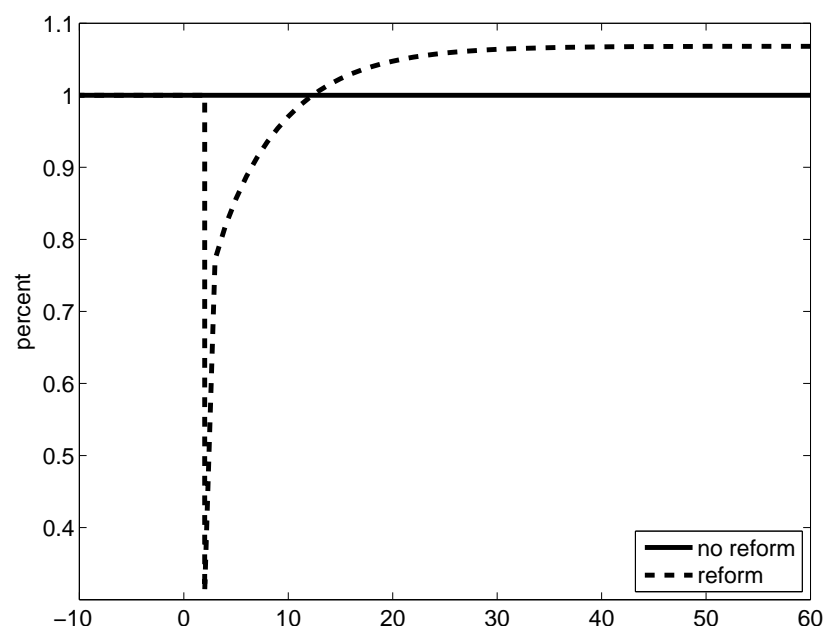

